\title{
EXTENSÃO UNIVERSITÁRIA NA PÓS-GRADUAÇÃO: IMPLANTAÇÃO DA RESIDÊNCIA PROFISSIONAL EM ARQUITETURA, URBANISMO E ENGENHARIA DA UFBA
}

EXTENSIÓN UNIVERSITÁRIA EN LA POSTGRADUACIÓN: IMPLEMENTASION DE LA RESIDENCIA
PROFISSIONALE EN ARQUITECTURA, URBANISMO E INGENIERÍA DE LA UFBA

UNIVERSITY EXTENSION IN GRADUATE COURSE: THE PROFESSIONAL RESIDENCY IMPLEMENTATION IN ARCHITECTURE, URBANISM AND ENGINEERING AT UFBA

\section{GORDILHO-SOUZA, ANGELA MARIA}

Arquiteta e Urbanista, Doutora, Profa.PPGAU UFBA, Proponente e Coordenadora da Residência AU+E/UFBA. E-mail: amgs@ufba.br

\section{ROCHA, HELIANA FARIA METTIG}

Arquiteta e Urbanista, Doutora, Profa. UFBA, Coordenadora de Disciplina na Residência AU+E/UFBA. E-mail: helianamettig@ufba.br

\section{INTRODUÇÃOO}

A Faculdade de Arquitetura da Universidade Federal da Bahia (FAUFBA), por meio do Programa de PósGraduação em Arquitetura e Urbanismo (PPGAU/UFBA) e do Laboratório de Habitação e Cidade (LabHabitar), em parceria com a Escola Politécnica (EP/UFBA), implantou de forma pioneira nessa área de atuação a Residência em Arquitetura, Urbanismo e Engenharia (Residência AU+E/UFBA), à semelhança da Residência Médica ${ }^{1}$. Na Residência AU+E/UFBA, a atuação se dá por meio do curso de Pós-Graduação lato sensu para Assistência Técnica em Habitação e Direito à Cidade, de caráter pluridisciplinar, oferta bianual, gratuito e voltado para capacitação profissional e cidadã. Almeja-se sua integração às instituições de interesse público, ampliando assim a inserção social da universidade pública (RESIDÊNCIA, 2013).

O objetivo principal é viabilizar, de forma sistemática e institucional, assistência técnica pública e gratuita em Arquitetura, Urbanismo e Engenharia, voltada para comunidades desassistidas e municípios demandantes, por meio de atividades integradas de ensino-pesquisa-extensão na pós-graduação, para elaboração, implementação e inovação de projetos nessas áreas de atuação.

Dentre os objetivos específicos, destacam-se:

a. Elaborar projetos com ênfase em habitação de interesse social e melhor qualidade de moradia;

b. Apoiar as comunidades e municípios envolvidos na elaboração de projetos para fomento e construção;

c. Capacitar profissionais e gestores como especialistas nessa área de atuação;

d. Promover oficinas e outras atividades que incorporem a participação das comunidades alvo e o fortalecimento da cidadania;

e. Incorporar as atividades extensionistas de assistência e inovação técnica à pós-graduação, de forma sistêmica e pluridisciplinar;

f. Incrementar a formação de rede nacional e intercâmbios internacionais para atuação e divulgação ampliada de informações e experiências desenvolvidas.

Tem-se como perspectiva a elaboração participativa de projetos de interesse social inovadores, visando ampliar o acesso a recursos públicos na promoção de melhor qualidade de moradia, inserção social e direito à cidade, alargando, também, o campo profissional. Para isso, além do curso, a Residência AU+E/UFBA 
abrange trabalho de campo para assistência técnica e elaboração de projetos, por meio de oficinas participativas, pesquisa, planejamento e outras atividades correlatas.

Essa proposta está pautada na Lei Federal $N^{\circ}$. 11.888, de 24 de dezembro, 2008, que assegura às famílias de baixa renda, de até 3 (três) salários mínimos, em áreas urbanas ou rurais, assistência técnica pública e gratuita para o projeto e a construção de habitação de interesse social, como parte integrante do direito social à moradia (BRASIL, 2008). Ainda sem regulamentação, dentre as várias possibilidades de atuação apontadas por essa legislação, está a residência profissional, vinculada às universidades. Sua implementação visa assim incrementar o direito à moradia, com base na Lei Federal No. 10.257/2001 do Estatuto das Cidades (BRASIL, 2001), na perspectiva ampliada do direito à cidade.

\section{BREVE HISTÓRICO}

A implantação deste curso no formato de Residência Profissional foi definida com base nas atividades implementadas pelo LabHabitar, laboratório criado desde 1993, no âmbito do PPGAU/FAUFBA, para desenvolver atividades de pesquisa, ensino e extensão voltadas para a relação entre habitação e cidade, integrando professores, pesquisadores e estudantes, de graduação e pós-graduação. ${ }^{2}$

A Residência AU+E/UFBA vem ampliar essa atuação e responder aos anseios de profissionais e dos movimentos sociais, voltados para a conquista de moradia digna e direito à cidade. Esta conjugação viabiliza pesquisa e capacitação para assistência técnica, de forma sistemática e contínua, frente à ampla e complexa problemática urbana nas cidades brasileiras.

Atualmente, na sua $3^{\underline{a}}$ edição 2017/18, a Residência AU+E/UFBA já capacitou 73 profissionais. Desde a $1^{\circ}$ edição 2013/14, os profissionais repassaram seus projetos para 24 comunidades na Região Metropolitana de Salvador e cidades das universidades nucleadas (UFPB, UNB, UFPel e UFCE). Este processo envolve diretamente centenas de participantes a cada edição bianual, com potencial de posterior implantação dos projetos elaborados, criando também demanda profissional nessa área de atuação.

Protagoniza, assim, a troca de saberes - conhecimento local e técnico - para novas alternativas de atuação em diferentes escalas e abrangência, numa perspectiva crítica, inventiva e propositiva, em prol do direito a cidades melhores e mais justas. Seus desdobramentos qualitativos e quantitativos subsidiam um acervo de referências projetuais, potencializando uma política universitária extensionista no âmbito da pós-graduação de forma continuada, com a implantação de um programa de residências profissionais multidisciplinares em rede nacional, com grande impacto social, diante da ampla demanda por esses serviços nas cidades brasileiras.

\section{ESTRUTURA E INSTALAÇÕES}

À semelhança da Residência Médica, essa capacitação profissional agrega teoria e prática. Para isso, envolve atividades de ensino, pesquisa aplicada, diagnósticos propositivos, seminários, oficinas junto às comunidades, com a devida tutoria a cargo dos professores credenciados. Culmina na elaboração de projetos que potencializam financiamentos para sua futura execução, com a devida anotação de responsabilidade técnica, para sua continuidade. Essa forma de atuação protagoniza, assim, novas alternativas para a conquista de moradia digna, podendo atuar em propostas na abrangência da casa, do bairro e da cidade, ou seja, promovendo assistência técnica nas escalas da edificação, da infraestrutura e dos espaços públicos, numa perspectiva educativa apoiada em diferentes abordagens e conhecimentos.

As atividades da Residência AU+E/UFBA integram um prazo mínimo de 14 (catorze) meses e máximo de 16 (dezesseis) meses, com um total de 40 (quarenta) créditos acadêmicos, desenvolvidos em um turno diário, matutino durante esse período. São 26 créditos ou 442 horas, sendo 340 horas-aula e 102 horas para elaboração do trabalho final (projeto e pesquisa orientada) e 14 créditos de trabalho de campo (mínimo de 840 horas de residência-assistência técnica), correspondendo aos seguintes módulos:

1‥ Período - Disciplinas, seminários e orientação do projeto a ser desenvolvido: total de 4 (quatro) meses.

2․ Período - Assistência Técnica para interação com as comunidades: de 8 (oito) a 10 meses.

3‥ Período - Elaboração e apresentação do Projeto Final Orientado: 2 (dois) meses.

As cinco disciplinas ministradas, coordenados por uma dupla de professores, são divididas em três módulos, permitindo, assim, um coletivo de professores mais amplo, com maior possibilidade de enriquecimento, troca e difusão dos conhecimentos, sendo uma delas em formato de seminários, com as seguintes temáticas: 1Produção do espaço, políticas urbanas e direto à cidade; 2- Planejamento e projeto de arquitetura, urbanismo 
e engenharia para assistência técnica; 3- Projetos de urbanização, infraestrutura e meio ambiente; 4Metodologias e técnicas para projetos participativos; 5- Seminários temáticos.

As atividades deste Curso de Especialização funcionam em sede própria, na FAUFBA, na Casa de Extensão dessa unidade. Integram-se, atualmente, ao seu quadro docente 54 professores e tutores credenciados (sendo 33 professores permanentes - integrantes da UFBA; 15 professores colaboradores e 6 professores nucleados - sem vínculo com a UFBA). A gestão deste curso se realiza por um Colegiado de 10 professores.

A Residência AU+E/UFBA já implantou nucleações em quatro universidades brasileiras: Universidade Federal da Paraíba; Universidade de Brasília; Universidade Federal de Pelotas e Universidade Federal do Ceará. Também integra nas suas atividades professores visitantes de outras instituições nacionais e internacionais, em convênios, seminários e oficinas, promovendo a discussão de projetos e tecnologias inovadoras de interesse social.

\section{ABORDAGEM TEÓRICO-METODOLÓGICA}

Integrando atividades de ensino, pesquisa e extensão universitária por meio de assistência técnica, essa iniciativa da Residência envolve múltiplos processos participativos, visando o papel de mediação proativa da academia em projetos de interesse social, sem caráter assistencialista. Traz também em perspectiva a necessária articulação entre universidades e gestão urbana e entre os cursos de graduação e pós-graduação, visando ao fortalecimento da capacitação profissional nessa área de atuação e os desdobramentos mais efetivos na promoção do direito à arquitetura, como um dos substratos do direito à cidade.

A abordagem tem como referência a relação entre habitação, comunidade e cidade, portanto para além da assistência técnica voltada para a construção da unidade habitacional, enfatizando nos projetos participativos os atributos de moradia e do direto à cidade. Isso reflete a importância dada tanto ao processo desenvolvido, como ao produto elaborado. A ideia de aprender com a cidade, em sua produção autogerida e coletiva, amplia a possibilidade propositiva na tomada de decisões, utilizando-se habilidades técnicas mais adequadas e o conhecimento dos moradores do seu lugar.

Nessa proposta pedagógica de aprimoramento coletivo, viabiliza-se, portanto, a aproximação da educação formal pluridisciplinar às práticas de produção da cidade e ao saber popular. Envolve para isso não apenas a participação de lideranças comunitárias, como também demais moradores de idades variadas, criando-se oportunidades educativas que lhes permitam exercer o papel de protagonista nas definições das melhorias necessárias ao seu ambiente de viver. Para isso são implementadas metodologias integrativas, utilizando-se técnicas como roda de diálogo e escuta, mapeamento do bairro e práticas facilitadoras da troca de saberes entre técnicos e moradores (ROCHA e MOURA, 2014).

Alguns dos princípios fundamentais que norteiam a implementação da Residência AU+E/UFBA são:

- Valorização das conquistas da comunidade, do ambiente e do local;

- Teoria e prática em processo participativo de definição de projeto;

- Dimensão interdisciplinar para educação, cidadania e capacidade de multiplicação;

- Participação da comunidade na definição de prioridades, no processo coletivo de discussões e mediação;

- Melhoria dos espaços públicos com projetos que venham a alcançar melhor qualidade de moradia;

- Concepção de projeto com base em aspectos éticos, estéticos e ambientais;

- Busca de tecnologias apropriadas às realidades locais, inovação e uso de materiais e recursos renováveis;

- $\quad$ Projetos de melhoria habitacional, espaços públicos, mobilidade, paisagismo, infraestrutura para o coletivo;

- $\quad$ Potencialização do ambiente de viver, preservação ambiental, segurança e sustentabilidade;

- Consideração de referências simbólicas, memória, cultura e inserção urbana;

- Entendimento da definição de projeto a partir de múltiplos aprendizados, troca de conhecimento e técnicas adequadas para a participação da comunidade;

- Desenvolvimento de metodologias abertas e oficinas experimentais com diversos grupos, trazendo memórias, legitimando conquistas de tecnologias criativas, sustentáveis e inclusivas;

- Aproximação com as escolas locais existentes, despertando a juventude local para a educação ambiental, direitos e deveres urbanos e o senso de pertencimento aos processos.

- Habitação compreendida além da moradia, ampliando a visão pelo Direito à Cidade;

Ampliam-se, assim, para além da inovação propositiva e projetual, novas possibilidades acadêmicas de política de pós-graduação em prol da formação continuada, multidisciplinar e inserção social da universidade, com perspectivas de expansão em rede nacional, portanto em grande escala, contribuindo, assim, para a conquista de cidades melhores e mais justas. 


\section{PRINCIPAIS RESULTADOS E DESAFIOS}

Atualmente, na sua 3aㅡ edição 2017/18, a Residência AU+E/UFBA já capacitou 73 profissionais. Desde a 1ำ edição 2013/14, os profissionais repassaram seus projetos para 24 comunidades na Região Metropolitana de Salvador e cidades das universidades nucleadas (UFPB, UNB, UFPel e UFCE). Este processo, envolve diretamente centenas de participantes a cada edição bianual, com potencial de posterior implantação dos projetos elaborados, criando também demanda profissional nessa área de atuação.

A implantação de Residência Profissional em outras universidades brasileiras traz o potencial de ser continuamente atualizado e replicado em programas de pós-graduação, para configurar uma rede de assistência técnica em escala nacional, ampliando sua atuação por meio de intercâmbios acadêmicos. Além disso, a cooperação com outras instituições da sociedade civil e entidades públicas alinhadas com os mesmos objetivos, fortalecem as possibilidades de fomento para implantação dos projetos.

Além da capacidade educativa fortalecida ao longo de todo o processo, são registrados ganhos específicos para todos os envolvidos - estudantes, profissionais, professores e comunidade -. O projeto final, repassado para a comunidade, contém as dimensões e especificações preliminares necessárias para atender a editais e Termo de Referência, sob a responsabilidade técnica do profissional-especialista.

Esta abordagem de educação continuada, no âmbito da pós-graduação, fundamenta-se no projeto urbano participativo e potencializa o diálogo entre a academia, comunidade e instituições públicas para ações propositivas. Amplia o papel social da universidade, ao mesmo tempo em que fortalece a capacidade dos profissionais recém-formados, tendo como meio o serviço-aprendizagem para projeto e planejamento socialmente engajados, com base em tecnologias socioespaciais e ambientais que dão suporte à capacidade transformativa urbana. Ao pôr em prática a referida Lei de Assistência Técnica, traz uma nova experiência no âmbito da universidade, na formação de profissionais habilitados nessa área e na constituição de novos arranjos sociais, com engajamento das comunidades envolvidas e apoio de entidades representativas.

Os limites e desafios a serem enfrentados situam-se sobretudo em investimentos sistemáticos nessa área de atuação. Aponta-se também a necessidade de custeio de bolsas trabalho de pós-graduação para os residentes-profissionais sem vínculo empregatício, bem como verba de auxilio-viagem para tutores e convidados externos, de forma a viabilizar uma maior interiorização, com atuação sistemática em municípios menores, altamente carentes de profissionais nessa área.

Neste dossiê, são apresentados a seguir alguns dos trabalhos finais da 1a. edição (2013/14), quando foram desenvolvidos 20 projetos de abrangência diversificada, em oito áreas e nove comunidades, a maioria de Salvador. O curso foi iniciado em setembro de 2013 e finalizado em dezembro de 2014, quando os resultados obtidos foram submetidos para apreciação das bancas de avaliação constituídas para examinaram o produto técnico e o processo de assistência técnica, esse último com base no depoimento dos tutores e comunidades envolvidas. Na finalização do curso, os projetos foram doados pelos seus autores às comunidades demandantes, visando desdobramentos para sua implementação.

A seleção dos projetos ora apresentados é representativa do conjunto de áreas trabalhadas nesta 1a. edição, com ênfase em projetos de arquitetura e urbanismo. Estes trazem diversas escalas de abrangência espacial, dialogando com os objetivos deste periódico. Importante observar na relação dos 20 projetos obtidos, que o Curso também absorve, em menor escala, profissionais de áreas afins, conforme ilustrado no quadro abaixo. Dessa forma, o conjunto de projetos finalizados nesta 1a. edição, além de proposições em arquitetura e urbanismo, revela outros alcances complementares a esse campo de atuação.

No atual momento em que se agudiza uma nova crise econômica e política no país, urge a necessária discussão da insuficiência de políticas de interesse social nas periferias e dos impactos de projetos excludentes na produção das cidades, mobilizando os segmentos envolvidos para a retomada de ações públicas em projetos adequados (GORDILHO-SOUZA, 2016). É preciso avançar com estratégias que potencializem iniciativas propositivas de emancipação social, a exemplo das atividades extensionistas a seguir apresentadas, em prol das mudanças necessárias para o alcance de cidades mais democráticas, acolhedoras e sustentáveis, na conquista pelo direito à cidade. 


\section{COMUNIDADES, TERRITÓRIOS E ASSISTÊNCIA TÉCNICA}

BREVE DESCRIÇÃO (CARACTERISTICAS DO LUGAR, DAS DEMANDAS E DA COMUNIDADE)

1) Jardim Nova Esperança - Salvador (ocupação consolidada próxima à uma represa/APA; praças e equipamentos coletivos, centro comunitário e regularização fundiária,); 2) Residencial Coração de Maria - Salvador (conjunto habitacional na periferia metropolitana, com questões ambientais e coletivas; espaços públicos, equipamentos e serviços); 3) Quilombo Rio dos Macacos Simões Filho, RMS (área de ocupação quilombola; delimitação territorial, infraestrutura e equipamentos); 4) Calabar e Alto das Pombas - Salvador (qualificação da ocupação urbana consolidada; mobilidade, drenagem, serviços, melhoria habitacional, regulamentação de ZEIS ); 5) Centro Histórico/ AMACH e Moradores de Rua (creche e proposta de habitação); 6) Gamboa de Baixo - Salvador (ocupação urbana consolidada - regularização fundiária, novas habitações e patrimônio); 7) Vila Dignidade - Ruy Barbosa/Ba (associação comunitária, melhorias na moradia, equipamentos, serviços, renda, áreas verdes e inserção urbana); 8) Vila Mangueira - João Pessoa/PB (equipamentos urbanos, espaços públicos e inserção urbana de ocupação recente).

Fonte: Elaborado pelas autoras com base nos trabalhos de conclusão da $1^{\text {a }}$. edição do curso.

Quadro 2 - Relação de trabalhos finais e autores, 1ª edição (2013/2014) da Residência AU+E/UFBA.

Os projetos assinalados em cinza estão apresentados neste dossiê.

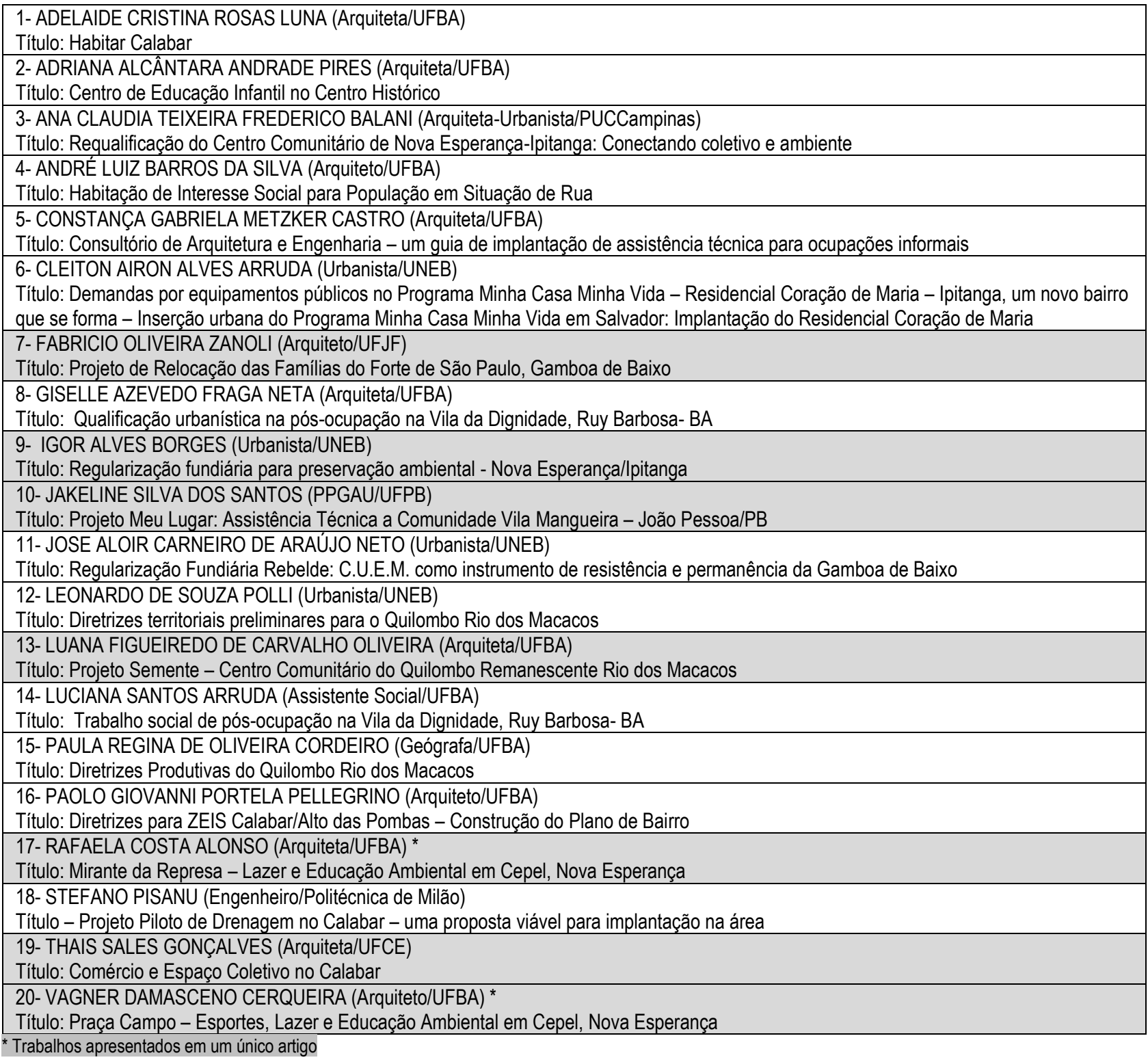




\section{REFERÊNCIAS}

BRASIL, Governo Federal. Lei № 10.257, de 10 de julho de 2001. [Estatuto da Cidade].

BRASIL, Governo Federal. LEI № 11.888, DE 24 DE DEZEMBRO DE 2008. [Assistência Técnica].

GORDILHO-SOUZA, A. M. Moradia Digna e Assistência Técnica: como os estudos, pesquisas e projetos de arquitetura e urbanismo estão avançando? In: Anais IV ENANPARQ - Encontro da Associação Nacional de Pesquisa e PósGraduação em Arquitetura e Urbanismo. Porto Alegre, 25 a 29 de Julho de 2016.

GORDILHO-SOUZA, Angela. LabHabitar e Residência AU+E/UFBA: do laboratório à prática, pelo direito à arquitetura, à habitação digna e à cidade. urbBA- 14 - Cidade, urbanismo e urbanidade: construído conceitos e práticas. Salvador-BA, 2014.

GORDILHO-SOUZA, A. M. Proposta de Curso de Especialização em Assistência Técnica, Habitação e Direito à Cidade - Implantação de Residência Profissional em Arquitetura, Urbanismo e Engenharia; apresentada ao PPGAU-FAUFBA, 2011.

LEFEBVRE, H. O Direito à Cidade. [Tradução Rubens Eduardo Frias]. São Paulo: Editora Moraes, 1991 [original,1968].

MINISTÉRIO DA EDUCAÇÃO. Residência Médica. Residência de Saúde. Disponível em: <http://portal.mec.gov.br/index. php? Itemid=506\&id=12263\&option=com_content\&view=article>Acesso em agosto/2013.

RESIDÊNCIA EM ARQUITETURA, URBANISMO E ENGENHARIA. Especialização em Assistência Técnica para Habitação e Direito à Cidade. UFBA. 2013. Disponível em <http://www.residencia-aue.ufba.br/>. Acesso em março de 2018.

ROCHA, H. F. Mettig; MOURA, M. S. Metodologias Integrativas em Projetos de Assistência Técnica para Comunidades Urbanas. jan./abr. 2016 v.5 n.1 p.153-166 ISSN: 2317-2428 copyright@2014 Disponível em: http://www.rigs.ufba.br Acesso em outubro/2016.

SANTOS, Boaventura de S. A Universidade do Século XXI: para uma reforma democrática e emancipatória da Universidade. São Paulo: Cortez, $3^{\underline{a}}$ ed., 2011.

\section{NOTAS}

${ }^{1}$ A Residência Médica no Brasil existe desde a década de 1940, para capacitação prática do médico recém-formado dentro de instituições de saúde, sob a orientação de profissionais médicos qualificados. Instituída pelo Decreto no 80.281, de 5/9/1977, que criou a Comissão Nacional de Residência Médica. Funciona como uma modalidade de pós-graduação, curso de especialização, com bolsas para os residentes. São oferecidas cerca de 27 mil vagas em 53 especialidades, para todo o país. Mais recentemente se ampliou para outras áreas de saúde, como Residência Multiprofissional (Residência Médica, 2013).

${ }^{2}$ Com base nas experiências desenvolvidas no LabHabitar-FAUFBA, implementou-se a proposta dessa Residência Profissional, sendo aprovada pela UFBA em 2011 (GORDILHO-SOUZA, 2011) Com a adesão de outros professores da UFBA, foi implantada em 2013. (Residência, 2013) Conceitualmente, inspira-se no pensamento de Henri Lefebvre, na sua clássica obra "O direito à cidade" (LEFEBVRE, 1968), nas contribuições de profissionais e movimentos sociais engajados por moradia digna no Brasil e em novos papeis a serem cumpridos pela Universidade em prol do processo emancipatório da sociedade (SANTOS, 2011).

NOTA DO EDITOR $\left(^{*}\right)$ O conteúdo do artigo e as imagens nele publicadas são de responsabilidade do(s) autor(es). 